\title{
Stimulating innovative activities in the university
}

\author{
Boris Lyamin ${ }^{1, *}$, Anna Sedyakina ${ }^{1}$, Grigoriy Chargaziya ${ }^{1}$, and Aleksandr Furin $^{2}$ \\ ${ }^{1}$ Peter the Great St. Petersburg Polytechnic University, 29, Polytechnicheskaya, 195251, St. \\ Petersburg, Russia \\ ${ }^{2}$ Volga State University of Technology, 3, Lenin Sq., 424000, Yoshkar-Ola, Russia
}

\begin{abstract}
As a result of the research, a way was created to stimulate the innovative activity of university employees. Existing university resources and mechanisms for converting resources into results are determined. Based on a study of the strategic goals of universities, the results that need to be obtained were determined. Graphs are constructed that determine the receipt of the necessary results through the use of various resources. Investigated was carried out of a focus group of university employees and their needs and capabilities were identified. A matrix has been constructed that classifies the columns that characterize the way employees are motivated, depending on their activities and age. Profiles were formed for each category of workers characterizing the most effective mechanisms for influencing workers to obtain the desired result. The results can be used in drawing up a plan of research activities of the university.
\end{abstract}

\section{Introduction}

Nowadays, universities use methods of stimulating scientific and pedagogical staff, based solely on financial motivation. Extremely small number of methods used implies any intangible incentives.

One of the promising motivating methods is called "Effective contract", which was described by Kurbatova M.V. and Donova I.V. [1]. "Effective contract" is an agreement between professor and university, which guarantees a high level of remuneration for the achievement of benchmarks, necessary for university.

The use of this method involves the division of research and pedagogical staff into groups. Belonging to a particular group determines the volume and structure of remuneration [1]. This division is presented in table 1.

\footnotetext{
*Corresponding author: lyamin.bm@gmail.com
} 
Table 1. The structure of research and pedagogical staff division in the framework of the "Effective contract" scheme.

\begin{tabular}{|l|c|c|c|}
\hline & $\begin{array}{c}\text { The level of academic } \\
\text { and administrative } \\
\text { workload }\end{array}$ & $\begin{array}{c}\text { Academic } \\
\text { remuneration }\end{array}$ & $\begin{array}{c}\text { Monetary } \\
\text { remuneration }\end{array}$ \\
\hline Assistants & Auxiliary work & Average & Low \\
\hline $\begin{array}{l}\text { Young } \\
\text { pedagogical staff }\end{array}$ & High & Average & Low \\
\hline $\begin{array}{l}\text { Net pedagogical } \\
\text { staff }\end{array}$ & High & Average & Average \\
\hline Research staff & Low & High & High \\
\hline
\end{tabular}

Nazarova I. [2] studies the salary structure of scientific and pedagogical staff. It consists of the base rate and variable remuneration due to incentive payments.

For example, mutual obligations of HSE scientific and pedagogical staff include [2]:

1) providing the employee with monetary remuneration and other conditions sufficient for successful professional work and ensuring a standard of living;

2) functioning of the requirements system for the quality of scientific, pedagogical and administrative activities; the use of a set of selective incentives that contribute to the development of the employee professional knowledge and skills; reducing the workload for employees who publish in international peer-reviewed journals $(25 \%)$, staff reserve members $(25 \%), \mathrm{PhD}$ holders hired in the international academic market, performing permanent administrative workloads (from 10 to $50 \%$ depending on the position);

3 ) provision of paid assistants from among the best students (564 people);

4) provision of paid creative vacation time (up to 6 months, after five years of work)

New strategic approaches to the university staff motivation are considered by Alaverdov A.R. [3] (table 2).

Table 2. Additional payment system.

\begin{tabular}{|l|c|}
\hline \multicolumn{1}{|c|}{ The list of fixed surcharges to the base rate } & $\begin{array}{c}\text { Surcharge amount, } \\
\text { \% }\end{array}$ \\
\hline $\begin{array}{l}\text { Surcharge for achieving the citation index established for this } \\
\text { position }\end{array}$ & 25 \\
\hline $\begin{array}{l}\text { Surcharge for the development and subsequent teaching of } \\
\text { copyright training courses (disciplines) }\end{array}$ & 25 \\
\hline Surcharge for teaching in a foreign language & 10 \\
\hline Surcharge for the use of innovative educational technologies & 15 \\
\hline Surcharge for the author's textbook & 15 \\
\hline $\begin{array}{l}\text { Surcharge for combining the functions of pedagogical staff and a } \\
\text { practicing part-time specialist working in the corresponding state or } \\
\text { private company }\end{array}$ & 10 \\
\hline Surcharge for the management of a scientific student association & \\
\hline
\end{tabular}

There are also two groups of bonuses. The first group is based on a competitive approach (e.g. for winning the contest Best professor of the year, Best Academic Supervisor of the Year, Author of the best pedagogical materials of the year, Author of the best textbook); the second is based on compensation approach (Surcharge for the implementation of the project, Surcharge for developing a new training course, necessary for the educational process). 
Within the framework of non-proprietary motivation, it is proposed to implement two approaches: the first is to increase the effectiveness of the work of the CPD by improving their qualifications (paid internships in the best foreign universities, medium-term retraining programs with an appropriate certificate and short-term continuing education programs for the best industry specialists), and the second is to conduct annual contests.

Blaskova M. and Trskova K. from University of Zilina (Slovakia) investigate the existence of a multifactorial effect on the activities of scientific and pedagogical staff and consider leadership style to be one of the important factors determining the effectiveness of innovative activities of university employees [4]. Thus, the study confirms the dependence of leadership style and level of motivation in all three motivational dimensions, while revealing the dependence of high rates of scientific and pedagogical staff on creating an atmosphere of trust in the team, belonging and encouraging new offers from employees.

Chairunnisa C. and Kosasih A. conducted a research of academic culture in the university and found that a comfortable working environment, which includes a sustainable organizational structure of the university, has a significant impact on the innovative activities of scientific and pedagogical staff [5].

After analyzing the work of scientists in the field of stimulating the innovative activity of scientists, it is worth noting that there are many in-depth researches of material incentives [6-17], however, the relationship between the results of innovative activity and the mechanisms for stimulating innovative activity of university employees has not been adequately research.

\section{Materials and methods}

The aim of this research is to identify the profiles of university employees to develop a more targeted motivation strategy. To achieve this aim it is necessary to solve a number of tasks:

- identify existing university resources and mechanisms for converting resources into results;

- based on the development strategy of universities determine the results that should be achieved;

- build graphs of obtaining the necessary results from various resources;

- conduct a focus group study to determine the needs and preferences of university employees;

- build a matrix classifying the needs of various categories of university employees;

- create employee profiles for each category.

To achieve the aim, general scientific research methods are applied that are focused on solving a set of scientific problems, such as analysis and synthesis, comparison, strategic analysis methods, systematic approach, structural-functional research method, as well as statistical data processing methods. As part of the research, a focus group survey was conducted to obtain delivery information from real scientists.

\section{Results}

As a result of the study, four main resources of the university were identified: financial, administrative, educational and methodological support for employees. Further, based on an analysis of the works cited in the literature review, proposals were identified for converting resources into results, which can conditionally be divided into financial and non-financial. Financial: remuneration for quality, increasing coefficient, remuneration for high intensity, remuneration for seniority. Non-financial: workload exemption, increasing the term of 
election for the post, creating a comfortable working atmosphere, including the availability of a modern material and technical base, granting special status and paid foreign internships (fig. 1)

The planned results were identified in the analysis of the requirements of international ratings, which take into account many factors. Thus, seven main required results of innovation activity at the university were identified: articles in highly rated Scopus or Web of Science journals; positive dynamics of citation index in Scopus or Web of Science; obtaining a patent; results of intellectual activity introduced into production; receiving grants; articles; high level of staff qualifications.

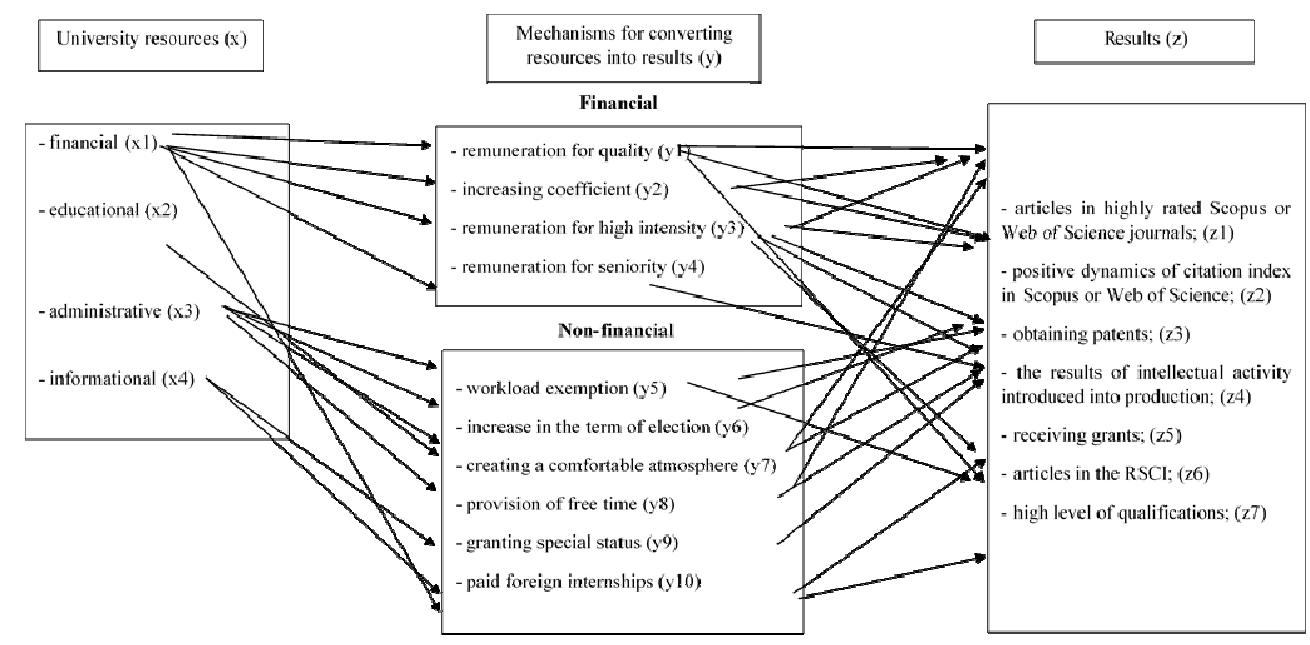

Fig. 1. Methods of motivating university staff.

From the considered enterprise resources, mechanisms for converting resources into results, we obtain graphs. The obtained columns (47) must be distributed among the categories of employees of the educational institution.

We can highlight four main categories of university employees: educational support staff, staff engaged in methodological work, staff primarily engaged in research activities, and researchers not involved in educational work. Within these categories, gradation by age was performed. Then a stratified selection of employees from various Russian universities was carried out according to such quota criteria as participation in research work, participation in educational work, and interest in implementing innovative activities at the university [18-19]. As a result, 80 people were surveyed who were suitable for the established requirements. Based on the data obtained and the generated graphs, we obtained a matrix classifying the graphs with the needs of various categories of university employees (Table 3).

Table 3. University staff motivation matrix.

\begin{tabular}{|c|c|c|c|c|}
\hline & $\begin{array}{c}\text { Educational } \\
\text { support staff }\end{array}$ & $\begin{array}{c}\text { Staff engaged in } \\
\text { methodological } \\
\text { work }\end{array}$ & $\begin{array}{c}\text { Staff primarily } \\
\text { engaged in research } \\
\text { work }\end{array}$ & $\begin{array}{c}\text { Researchers not } \\
\text { involved in } \\
\text { educational work }\end{array}$ \\
\hline $21-25$ & $\mathrm{G} 6$ & $\mathrm{G} 39, \mathrm{G} 44, \mathrm{G} 46$, & $\mathrm{G} 39, \mathrm{G} 44, \mathrm{G} 46$, & $\mathrm{G} 39, \mathrm{G} 44, \mathrm{G} 1$ \\
\hline $26-30$ & $\mathrm{G} 6, \mathrm{G} 40, \mathrm{G} 41$ & $\mathrm{G} 40, \mathrm{G} 42, \mathrm{G} 44$ & $\mathrm{G} 42, \mathrm{G} 40, \mathrm{G} 23$ & $\mathrm{G} 42, \mathrm{G} 40, \mathrm{G} 17$ \\
\hline $31-35$ & $\mathrm{G} 6, \mathrm{G} 40, \mathrm{G} 41$ & $\mathrm{G} 41, \mathrm{G} 42, \mathrm{G} 44$ & $\mathrm{G} 47, \mathrm{G} 38, \mathrm{G} 33$ & $\mathrm{G} 47, \mathrm{G} 38, \mathrm{G} 35$ \\
\hline $36-40$ & $\mathrm{G} 6, \mathrm{G} 40, \mathrm{G} 41$ & $\mathrm{G} 25, \mathrm{G} 1, \mathrm{G} 45$ & $\mathrm{G} 47, \mathrm{G} 38, \mathrm{G} 36$ & $\mathrm{G} 47, \mathrm{G} 38, \mathrm{G} 36$ \\
\hline $41-45$ & $\mathrm{G} 6, \mathrm{G} 40, \mathrm{G} 41$ & $\mathrm{G} 37, \mathrm{G} 29$ & $\mathrm{G} 36, \mathrm{G} 33, \mathrm{G} 23$ & $\mathrm{G} 36, \mathrm{G} 28, \mathrm{G} 17$ \\
\hline $46+$ & $\mathrm{G} 6, \mathrm{G} 40, \mathrm{G} 41$ & $\mathrm{G} 35, \mathrm{G} 46$, & $\mathrm{G} 29, \mathrm{G} 35, \mathrm{G} 23$ & $\mathrm{G} 29, \mathrm{G} 35, \mathrm{G} 17$ \\
\hline
\end{tabular}


As a result of the research, suggestions were identified on the motivation of university employees' innovative activities, depending on the activities they perform and age:

- For educational support staff, an important factor in motivation is an increase in wages depending on the quality of the work they perform. Based on the data of the focus group survey, it was revealed that the educational and support employees need internships in other universities, including foreign ones, in order to improve their qualification.

- Staff engaged in methodological work notes that for more effective work, they need to be provided an allowance for the quality of work performed, to create a comfortable working atmosphere, and also to relieve part of the workload in order to form a closer relationship with the real sector of the economy.

- Staff primarily engaged in research work, is ready to work more productively, if provided allowances for quality, a comfortable atmosphere, a certain status (young scientist of the year, professor of the year, etc.), and less workload. It is worth noting that the release of faculty from part of the workload in this case is necessary in order for them to be able to form better applications to scientific foundations and publish articles in journals with a higher rating.

- Researchers not involved in educational work. This category of personnel has opportunities to create a large number of high-quality innovation activities. To motivate this category, an allowance is required for the quality of work performed, obtaining a certain status, as well as creating a comfortable working atmosphere. (fig. 2)

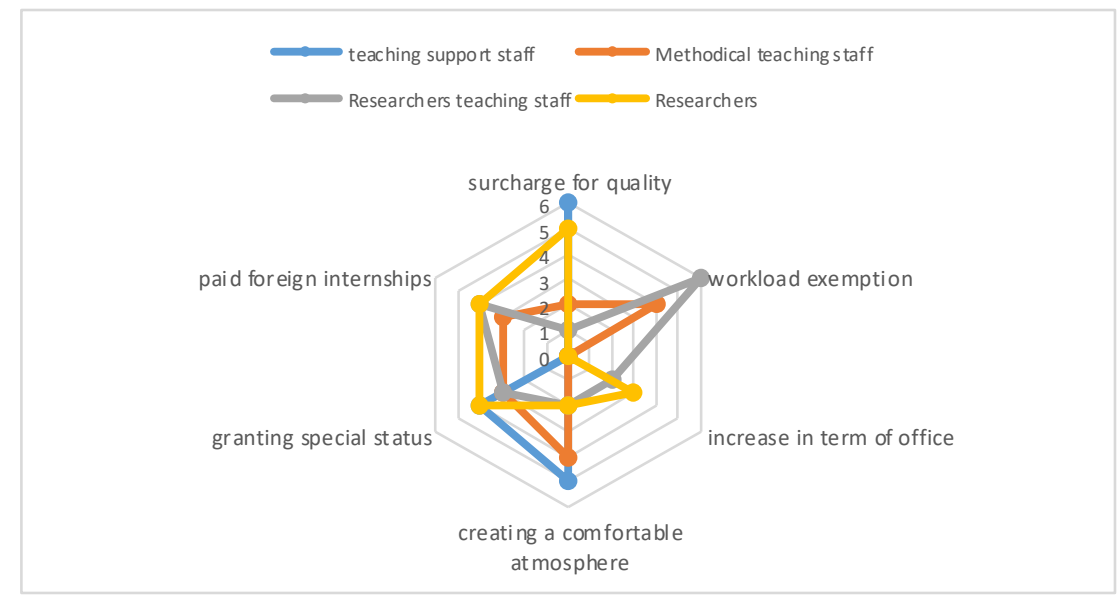

Fig. 2. Profiles of university employees based on the activities they perform.

At the same time, there is a tendency towards a decrease in interest in foreign internships with an increase in the age of educational staff. So, educational staff of 21-35 years old prefer foreign internships, they are mainly interested in increasing the term of election for educational staff from 36 years and older.

Based on the information received in the course of the study, we can create profiles of university employees based on the activities they perform that can be used to build a staff motivation strategy.

\section{Discussion}

The revealed profiles of university employees confirm the need to distinguish the categories of scientific and pedagogical staff depending on their financial remuneration, academic and administrative workload, or intangible remuneration. The analysis of the results of the focus 
group survey confirms the effectiveness of the proposed activities. Further research should take into account the experience of Alaverdov A.R. regarding material incentives for employees. Accordingly, the results of the research can be applied to build an effective motivation system for scientific and pedagogical staff.

\section{Conclusion}

As a result of the research, a way was created to stimulate the innovative activity of scientific and pedagogical staff. Existing university resources and mechanisms for converting resources into results were identified. Based on a study of the strategic objectives of universities, the results were determined that should be achieved in the short and medium term. Graphs were constructed that characterize the ways to obtain the necessary results through the use of various resources. A study of the focus group of scientific and pedagogical staff was carried out and their needs and capabilities were identified. A matrix was constructed that most fully characterize the way employees are motivated, depending on their activities and age. Profiles were formed for each category of workers characterizing the most effective mechanisms for influencing workers to obtain the desired result. The obtained data can be used in drawing up a plan of research activity of both the structural unit and the university as a whole.

\section{References}

1. M.V. Kurbatova, I.V. Donova, Journal of Institutional Studies 11(2) (2019) DOI: 10.17835/2076-6297.2019.11.2.122-145

2. I.B. Nazarova, E.S. Balabanova, A.O. Grudzinskii, and others, Russian Education and Society 48, 40-57 (2006) DOI: 10.2753/RES1060-9393480704

3. A.R. Alaverdov, Vysshee Obrazovanie v Rossii 28, 23-36 (2019) DOI: 10.31992/08693617-2019-28-2-23-36

4. M. Blašková, K. Trskova, New Trends and Issues Proceedings on Humanities and Social Sciences 3, 23-34 (2017) DOI: 10.18844/gjhss.v3i4.1510

5. C. Chairunnisa, A. Kosasih, The Journal of Social Sciences Research, 1850-1854 (2019) DOI: $10.32861 /$ jssr.512.1850.1854

6. E.A. Konnikov, O.A. Konnikova, D.G. Rodionov, Resources 1, 20 (2019) DOI: 10.3390/resources8010020

7. D.G. Rodionov, E.A. Konnikov, O.A. Konnikova, Journal of Social Sciences Research 3, 277-282 (2018) https://www.researchgate.net/publication/330039814_Approaches_ to_ensuring_the_sustainability_of_industrial_enterprises_of_different_technological_evels

8. E.A. Konnikov, O.A. Konnikova, S.A. Ivanov, O.V. Novikova, Proceedings of the 31st International Business Information Management Association Conference, 52185225 (2018)

9. E.A. Konnikov, O.A. Konnikova, T.V. Bogacheva, O.U. Yuldasheva, Proceedings of the 31st International Business Information Management Association Conference, 5226-5232 (2018) https://ibima.org/accepted-paper/the-study-of-the-conformity-ofmarketing-solutions-to-the-concept-of-sustainable-consumption/

10. E.A. Konnikov, O.A. Konnikova, D.S. Negashev, A.V. Novikova, Proceedings of the 32nd International Business Information Management Association Conference, 44314444 (2018) 
11. E. Konnikov, O. Konnikova, V. Leventsov, IOP Conference Series: Materials Science and Engineering 497 (2019) DOI: 10.1088/1757-899X/497/1/012043

12. I. Rudskaia, D. Rodionov, The concept of total innovation management as a mechanism to enhance the competitiveness of the national innovation system (2018) DOI: $10.1145 / 3230348.3230349$

13. L.V. Nikolova, D.G. Rodionov, N.V. Afanasyeva, Impact of globalization on innovation project risks estimation 20(2), 396-410 (2017) https://www.ersj.eu/journal/687

14. A.S. Sokolitsyn, I.I. Kovalenko, A.V. Zvontsov, Production risk economic assessment based on the fuzzy logic approaches (2017)DOI: 10.1109/SCM.2017.7970738

15. I. Krasyuk, T. Kirillova, V. Bakharev, B. Lyamin, IOP Conference Series: Materials Science and Engineering, 012125 (2019) DOI: 10.1088/1757-899X/497/1/012125

16. B.M. Lyamin, I.A. Krasyuk, Smart Innovation, Systems and Technologies 139, 388397 (2019) DOI: 10.1007/978-3-030-18553-4_49

17. B. Lyamin, E. Shepeleva, I. Krasyuk, IBIMA 2019: Education Excellence and Innovation Management through Vision 2020 (2019) https://ibima.org/acceptedpaper/analysis-of-the-key-factors-influencing-on-the-innovative-business-processes-ofthe-russian-enterprises/

18. S. Bozhuk, N. Pletneva, Electric Cars as a Case Study 692, 1234-1242 (2018) DOI: 10.1007/978-3-319-70987-1_132

19. S. Bozhuk, N. Krasnostavskaia, T. Maslova, N. Pletneva, IOP Conf. Ser.: Mater. Sci. Eng. 497, 012115 (2019) DOI: 10.1088/1757-899X/497/1/012115

20. Z. Yordanova, A model for evaluation of innovative universities, 459-462 (2019) DOI: 10.35745/ecei2019v2.117 